\title{
QUEEN'S
UNIVERSITY
BELFAST
}

\section{Stepping Off the Career Ladder: Exploring the Impact of Career Shocks on Women's Career Decisions in the UK}

Mazzetti, A. (2020). Stepping Off the Career Ladder: Exploring the Impact of Career Shocks on Women's Career Decisions in the UK. In Career Dynamics in a Global World (pp. 80-95). Edward Elgar Publishing.

\section{Published in:}

Career Dynamics in a Global World

\section{Document Version:}

Peer reviewed version

Queen's University Belfast - Research Portal:

Link to publication record in Queen's University Belfast Research Portal

\section{Publisher rights}

Copyright 2020 Edward Elgar Publishing Ltd.

This work is made available online in accordance with the publisher's policies. Please refer to any applicable terms of use of the publisher.

\section{General rights}

Copyright for the publications made accessible via the Queen's University Belfast Research Portal is retained by the author(s) and / or other copyright owners and it is a condition of accessing these publications that users recognise and abide by the legal requirements associated with these rights.

Take down policy

The Research Portal is Queen's institutional repository that provides access to Queen's research output. Every effort has been made to ensure that content in the Research Portal does not infringe any person's rights, or applicable UK laws. If you discover content in the Research Portal that you believe breaches copyright or violates any law, please contact openaccess@qub.ac.uk. 
$<a>$ Stepping Off the Career Ladder: Exploring the Impact of Career Shocks on Women's Career Decisions in the UK

\section{$<$ b $>$ Introduction}

A recent review of female representation across all management levels in the UK highlighted that the attrition rate for women progressing from junior to senior management levels is high (CMI, 2013a). The report highlighted that although women make up 60 per cent of junior management positions, only 20 per cent make up senior management positions, and when considering the number of women in CEO or board positions, the percentage is in single figures. This is despite significant efforts over the past decades to tackle gender discrimination and female underrepresentation in the UK (CIPD, 2018). However, this is not just a UK phenomenon, it is much the same picture across most of Europe, the US, and Australia (Davies, 2015; Johnston and Lee, 2012). The consensus is that this 'leaking pipeline' of women is partly due to the 'glass ceiling' and partly due to the 'glass obstacle course' (CMI, 2013a). The 'glass ceiling refers to the inherent structural and discriminatory practices that prevent women progressing to more senior management levels (CIPD, 2018; Davies, 2015; Johnston and Lee, 2012). The 'glass obstacle course' refers to the unseen hurdles and barriers that stop or dissuade women from progressing their management careers (CMI, 2013a; Davies, 2015). Much research has focused on the former, discriminatory practices such as the gender pay gap that prevent women from entering higher management levels (Johnston and Lee, 2012). However, less is known about the latter, the reasons why women decide not to climb the career ladder in the first place or opt to 'step off' the career ladder (CMI, 2013a; CMI, 2013b).

There is a general consensus that the decision-making process behind women's career-planning is different to that of men (Astin, 1984; Mavin et al., 2015; O'Neil and Bilimoria, 2005; Scott and Hatalla 1990) because of the broader cultural and social contexts underpinning women's careers (Astin, 1984; Hoffarth, 1996). For example, O'Neil and Bilimoria (2005) suggest that women more generally have to juggle the role of providing dependent care with their work role and that this inherent role duality pervades women's career decisions and choices. Consequently, they suggest that this combination of factors uniquely constrains women's careers.

This chapter aims to provide a better insight into the thinking behind a group of women and their decisions to 'step off' their career ladders. Drawing on the 
findings of a wider study exploring career transitions, this chapter presents the experiences of eight women who encountered 'career shocks', conceptualised as significant events that led to the women 'taking stock' of their career options. Research has highlighted that career shocks may influence employees' intentions to voluntarily quit their jobs (Holtom et al., 2005; Lee and Mitchell, 1994). Applying the lens of conservation of resources theory, this chapter explores how a lack of access to appropriate coping resources impacted the women's decisions to 'step off' their management career ladders and seek out alternative career options. With a growing recognition of the business case for having women at senior levels in organisations (Carter et al., 2003: CIPD, 2018), this chapter provides insights into how both organisations and individuals may incorporate career shocks into their career development plans.

\section{$<b>$ Theoretical Underpinnings $<$ c $>$ Defining Career Shocks}

Despite investing time and energy into planning out a career path, an individual does not always have control over how his or her career will evolve (Sullivan et al., 2003). For example, an individual may have agency to trigger transitions such as taking on a new role or applying for a promotion, however there will be little agency involved in transitions such as being laid off or having to cope with the effects of long-term illness. In their review of the literature on trending topics in career development, Akkermans and Kubasch (2017) highlight that in contemporary career literature there has been much focus on individual agency, but there is limited reference to the impact that unexpected and externally triggered events may have on individual career paths. Akkermans et al. (2018:4) note that careers research needs to reflect on the impact of 'career shocks', events that have a significant impact on individual career plans, which they define as:

A disruptive and extraordinary event that is at least to some degree, caused by factors outside the focal individual's control and that triggers a deliberate thought process concerning one's career. The occurrence of a career shock 
can vary in terms of predictability, and can be either positively or negatively valanced.

There are a number of components to this definition which are worthy of further discussion. First, career shocks are significant events that are experienced by most individuals over their life course (Scott and Hatalla, 1990). They may occur in the personal domain (for example an illness) or in the organisational domain (for example a company merger) (Lee and Mitchell, 1994). Second, shocks may be experienced negatively, neutrally, or positively (Akkermans et al., 2018; Lee and Mitchell, 1994; Seibert et al., 2013). For example, taking on a promotion is likely to be a positive experience, a new line manager may be a neutral experience, and a layoff is likely to be a negative experience (Holtom el at, 2005).

Third, career shocks are generally unexpected and outside the control of the individual. As such, there is limited opportunity for pre-emptive and proactive planning (Akkermans et al., 2018; Holtom et al., 2005). Akkermans et al. (2018) distinguish between predictability and controllability and stress that the degree of predictability and controllability may have differential impact on shock valence and career decisions. For example, having a child is a relatively predictable and controllable event and likely to be positively valanced however, encountering postnatal health issues for either the mother or the child is less predictable or controllable and likely to be negatively valanced. Finally, career shocks initiate a deliberate thought process about careers (Akkermans et al., 2018; Holtom et al., 2005; Lee and Mitchell, 1996). Holtom et al. (2005: 341) define a career shock as 'a distinguishable event that jars an employee toward deliberate judgements about his or her job'. As such, fundamental to the concept of career shocks, is that they trigger individuals to 'take stock' and evaluate their careers, prompting them to make specific career decisions that may substantially alter their personal career plans (Akkermans et al., 2018; Bright et al., 2005; Holtom et al., 2005; Lee and Mitchell, 1994; Siebert et al., 2013). Career shocks have the potential therefore to impact both personal and organisational career development plans (Akkermans et al., 2018; Holtom et al., 2005). 
A central tenet of conservation of resources theory is that individuals strive to acquire and preserve the resources they value (Hobfoll, 1998, 2001). Hobfoll categorises resources as object resources (such as a house), personal characteristics (such as self-efficacy), condition resources (such as status), and energies (such as hope). Stress occurs when (1) individuals are threatened with the loss of their valued resources; (2) valued resources are lost; or (3) individuals fail to gain valued resources despite significant personal investment (Hobfoll, 2001). Furthermore, Hobfoll (2001) notes that resource loss begets further resource loss (resource spirals), while resource gain begets further gain (resource caravans).

Within the workplace resources have an intrinsic value and as such a motivating effect, as they not only buffer against the demands of the workplace but may also form a basis for flourishing and growth (Gorgievski et al., 2011). Hobfoll (2011) therefore notes that organisations can either create conditions that support and foster individual resource investment or an environment that undermines investment. He posits that organisations that imbue employees with the necessary resources and provide a climate of safety and stability, will benefit in terms of greater employee resilience, commitment and engagement. Alternatively, he posits that organisations that do not deliver a resource enhancing ecology will struggle to sustain long-term employee investment.

\section{$<b>$ Research Design and Participants}

Visual research methods have been used successfully in studies which focus on transition (for example Barner, 2008; Stiles, 2004 ). This study adopted a timeline structure to enable chronology and sequencing of events, retrospection and sense making (Chell, 2004; Cohen and Mallon, 2001). Additionally, drawing was adopted to facilitate the exploration of complex, multifaceted, and emotive issues that are often difficult to articulate verbally (Bagnoli, 2009; Barner, 2008; Broussine, 2008; Meyer, 1991; Stiles, 2004; Warren, 2009). Participants were recruited using a snowball sampling strategy and were invited to participate in a one-to-one interview. At the time of the study, they had all held, or were currently employed in, a range of management positions. The women in the study were aged between 30 and 70 and were based in the UK. The women 'drew' a timeline of their careers and included emoticons (smiley faces or sad faces) to symbolise positively valanced and 
negatively valanced career shocks. .The 'visual timelines' approach enabled a range of career shocks to be explored over the timeline of a career, facilitating an analysis of the factors informing 'positive' or 'negative' appraisal (Mazzetti, 2014; Mazzetti and Blenkinsopp, 2012). ${ }^{1}$

\section{$<$ b Findings}

While not a homogenous group, the women shared many similar career shocks. Analysis of the data highlighted four key themes worthy of further discussion as they ultimately influenced the women's' decisions to 'step off' the career ladder. For each theme a vignette is presented to explore the themes in more detail. The names used in the vignettes are pseudonyms and some details have been omitted to protect the identity of the participants. The notes in italics refer to the notes written on the timelines by the participants.

\section{$<c>$ Inputs versus Outputs Imbalance}

Vignette 1: Jessica considered that gaining a senior role with prestige and status had been a significant achievement in her career. She drew a smiling medal with the word ' $1 \mathrm{~s}^{\mathrm{s}}$ ' on her timeline and a picture of herself celebrating on top of a high building. She described the benefits of being in this position using the words 'more money, esteem, status and recognition' on her timeline. However, she described that over a four-year period, she had to invest significantly to stay 'on-top'. She noted on her timeline that she was working 60 hours a week to meet her 'senior management team high standards of work quality'. She considered that her role had become a 'prison with no release'. She noted on her chart 'fear of falling' as she feared that the investment required to sustain the performance levels required was having an adverse impact on her health and her family. When she was diagnosed with a serious illness, Jessica considered that she had reached 'breaking point' and needed to revaluate the investment of her time. She experienced this as being a very stressful time during which she felt 'confused'. After 18 months of illness and sick leave during which time she felt let down by the 'lack of support' from her

\footnotetext{
${ }^{1}$ Pictures from the timelines are available from the author.
} 
organisation, Jessica decided to resign from her position. Jessica was still considering her future career options at the time of our discussion.

Jessica's story illustrates how an initially positively valanced career shock, a promotion, can, over time, become negatively valanced Her failing health and worries about being able to sustain the level of investment in her role ultimately led her to leave her organisation. In the context of conservation of resources theory, she had invested considerable personal resources (in terms of time, commitment and personal sacrifice) and yet she perceived they had not been justly rewarded by her organisation in terms of condition resources (organisational support), or energy resources (time to recover from her illness). This perceived input / output imbalance ultimately led her to leave her organisation.

\section{<c> Unsupportive Line Managers}

Vignette 2: June considered her experience of extended absence from work due to routine surgery to be a significantly stressful period in her career. At the time, June had held a senior management position and noted on her timeline that she had always had a 'bumpy' relationship with her line manager. However, it was her line manager's handling of her absence that 'broke the relationship'. June described her pre-operation handover meeting as 'an outer body experience' as she 'watched as they dismantled all [she] had achieved'. After the surgery, June talked about struggling with her marginalisation from her work identity. She explained that she 'checked emails hourly' as she feared she was missing out on what was happening at work. She felt 'lonely and forgotten' as she had limited contact with her organisation. On her timeline, June noted 'THAT meeting', to describe a tense visit she had experienced with her line manager about her return to work. At the meeting her manager made it clear that she did not want June to return to her 'old' role, and instead offered her a 'sideways move', a role that June considered was 'less prestigious'. June considered that the move had sent her 'back to the start again'. On her return to work, June talked about her struggle to 'reconnect', 'rebuild identity' and 'rebuild self'. After a short period in her new role, June decided to leave the organisation She was still considering her future options when we met. 
June's vignette highlights the issue of the controllability of career shocks and the impact that line managers have on their handling of career shock episodes. Although her routine operation was a predictable event, the process of how her absence was managed was controlled by her manager. Having limited control over the direction of her career, was her catalyst to 'step off' her career ladder. Considering the lens of conservation of resources theory, poor leadership created an environment in which she experienced the loss of condition resources (a supportive work environment) and personal resources (self-esteem and confidence).

\section{$<c>$ Work Life Balance}

Vignette 3: Jillian relocated with her husband to the US. Before the relocation, she had been working in a senior professional role that demanded 'significant collaboration and decision making'. Not only did she have to leave her job and relocate, but she also had to leave her family support network who had helped her in the UK with childcare. Jillian explained that initially she had enjoyed the break from her stressful role, but she was mindful that she did not want to become 'bored', 'Ionely' or 'deskilled'. Jillian decided to volunteer her professional services for a number of community groups and charities in her new area. She considered that this enabled her to keep up-to-date with the professional world to which she belonged. After eight years, the family relocated back to the UK and Jillian took up another senior role. She had considered that her volunteering roles had enabled her not only to explain the gap in her CV but also to keep her skills current. When we met, she was still active in her local community and had continued to voluntarily offer her professional services to a number of charity organisations.

Jillian's story highlights how a sense of agency and control in developing the 'future' self may positively influence uncontrollable career shocks. Jillian was proactive in investing her time to plan for her future career by volunteering her skills for community organisations as a means of keeping up-to-date with developments in her profession. In terms of conservation of resources theory, Jillian had to deal with a number of resource losses. However, she focused on investing her time into developing future personal and energy resources in terms of enhanced skills and knowledge. 


\section{$<$ C $>$ A Series of Career Shocks}

Vignette 4: Over a two-year period, Jane noted a series of significant events including her husband's setting up of a new business and their relocation to a new area to live and work, a difficult relationship with her new line manager, the death of a close family member and the birth of their first child. Jane discussed how this was an overwhelming time for her and she had subsequently taken a period of sickness absence due to stress and depression. On her timeline she noted 'new baby, new business, no family, no friends, no job, no confidence'. Jane's feelings were further exacerbated by the lack of routine she was experiencing due to being away from work and the difficulties she was having in adjusting to her medication. As the time approached for her to return to work, Jane explained that she doubted her ability to return. She noted on her timeline, 'can I still do this?' Jane discussed how her lack of confidence was a key factor in her decision to leave her job. She considered that the decline in her self-confidence was caused by her manager who "kept questioning [her] judgement' and also by her conflicting emotions during her period of absence, noting that she had difficulty trying to define and identify who she had become. However, Jane noted that her decision to leave had created further anxieties and 'feelings of failure'. Jane highlighted that she had also been concerned about the impact that a break in her career due to stress and depression might have on her future career prospects. She noted 'I'll never get another job if they think I'm a headcase ${ }^{2}$

The use of the timelines approach enabled the chronology and sequencing of events to be captured. A frequent observation was the number of shocks that can happen within a relatively short space of time. Jane's story highlights the intense impact of a series of career shocks on personal well-being, sense of self, and selfconfidence in one's abilities. Her lack of self-confidence and her concerns over how her period of absence would be perceived by others, had left her doubting if she would be able to re-enter the workplace. In the context of conservation of resources theory, she experienced a resource spiral as initial resource losses begat further resource losses.

\footnotetext{
${ }^{2}$ A colloquial term for 'being mad'.
} 


\section{$<b>$ Discussion}

The women's stories highlight the significant impact that career shocks can have on individual well-being and commitment to engage with their organisation. From an individual's perspective, career shocks create uncertainty (Akkermans et al., 2018) as they disrupt the normal way of functioning and have the potential to conflict with personal goals, values, and aspirations (Lazarus, 1999). Shocks may also place too much of a demand on an individual and tax his or her available coping resources (Halbesleben et al., 2014). Furthermore, career shocks are likely to disrupt personal evaluations of career image and identity (Akkermans et al., 2018) by disrupting the coherence of personal career 'stories' forcing individuals to engage in identity work to make sense of their world (Ibarra, 2003; Ibarra and Lineback, 2005). Career shocks therefore have the potential to be salient stressors impacting individual wellbeing, and 'sense of self' (Sveningsson and Alvesson, 2003). From an organisational perspective, career shocks may lead to individuals disengaging with their organisations (Halbesleben, 2006) or quitting their organisations in order to pursue alternative career paths (Holtom et al., 2005). In the context of 'the leaky pipeline' career shocks may force women to evaluate their careers and decide that walking away from their careers is their best option. As such, a better understanding of the impact of career shocks may help organisations address this dysfunctional labour turnover (Lee and Mitchell, 1994). Drawing on the findings from this research study, three recommendations are put forward to facilitate the incorporation of career shocks into personal career planning and organisational talent and retention planning. These will now be discussed in more detail.

\section{$<\mathrm{c}>$ Creating Resource Enhancing Work Environments}

Many of the women talked about their perceived imbalance between the efforts put in to sustain their role and the output they received in terms of organisational support and acknowledgement. Elraz (2018) highlights that high-performance cultures place a high value on performance and achievements, and as such, there is a negative perception of those who are perceived as not performing to the culturally established norm (see also Chapter X of Datta and Shah). O'Neil and Bilimoria (2005) highlight that male-defined perceptions of performance pervade organisational work cultures 
and as such, Mavin et al. (2015: 312) suggest that women will frequently have to confront 'masculine heroic leader expectations' of performance. Organisations therefore need to address the issue of how 'performance' is culturally defined and measured within their institutions (CMI, 2013b; Mavin et al, 2015). Women's definitions of merit might look different to men's and therefore, organisations need to acknowledge that there is more than one predefined 'norm' (CMI, 2013a).

Organisations should strive to foster a more supportive performance culture, for example, by measuring performance in terms of one's output rather than by hours spent at one's desk (CMI, 2014).

Additionally, women still tend to take on the primary care-giver roles for both children and other dependents, and their career decisions are moulded by workfamily pressures (O'Neil and Bilimoria, 2005). Women therefore often make 'satisficing choices', putting their families' well-being before their career advancement (see also Chapter X of Datta and Shah). Recent research suggests that childcare is still one of the main barriers to women progressing in the workplace accounting for women in their late twenties and thirties dropping out of the workforce and women in their forties failing to return (CMI, 2013b). There is therefore a need to foster more inclusive work cultures that provide women with the condition resources (for example, in terms of flexible working patterns) to enable women to continue in their careers whilst continuing to maintain their family responsibilities (O'Neil and Bilimoria, 2005). Bardoel et al. (2014) suggest a range of supportive work practices such as the development of strong workplace social support networks; occupational health, safety and employee assistance programmes; and flexible work arrangements, reward and benefits systems. Furthermore, organisations need to invest in the training and development of line managers not only to enable them to implement more inclusive measures of performance (CMI, 2014) but also to address negative work relationships that lead to employee depersonalisation and disengagement (Halbesleben, 2006).

\section{$<c>$ Investment in Early Support Interventions}

The loss of one resource begets the loss of other resources (Hobfoll, 2001). As such, it is imperative that organisations create 'resource caravans' that can ameliorate the impact of resource loss (Hobfoll, 2011). Hobfoll (2001) posits that the value ascribed to resources may be specific to the organisational context (such as prestige and 
status) or more universal (such as health, well-being, and a positive sense of self). Five of the women in this study had experienced periods of ill health. Elraz (2018) suggests that it is difficult for someone who is ill to situate themselves within a highperformance culture as they not only have to invest resources into managing their condition but also into managing the stigma associated with poor performance. She highlights that this may have a knock-on impact in terms of a worsening of their condition. Foster (2017) further suggests that this may be particularly the case for those with 'invisible' disorders such as mental health conditions. She suggests that a focus on 'ableism' may prevent disclosure of invisible conditions leading to a worsening of health. Some of the women talked about their reluctance to disclose their conditions, and this was particularly the case for those dealing with stress, anxiety and depression. They considered their work cultures a contributing factor to the worsening of their condition. For some this impacted their ongoing willingness to engage with their organisation; and for others contributed to their resource spiral. This highlights the need for organisations to deal with the issue of stigma and to develop a climate of trust to facilitate early interventions which may ultimately provide the necessary nurturing climate for both a safe disclosure of the condition and also a successful return to work (Follmer and Jones, 2018; Leufstadiusa et al., 2009). For example, Follmer and Jones (2018) suggest peer support networks, regular union and employee communications, strong employee assistance programmes, and continuous contact between the organisation and employees during a period of sickness absence.

\section{$<c>$ Woman as Project}

Mavin et al. (2015) suggest that the work-life interface should not be a barrier to women progressing in their careers as women should take agency in both balancing their work and family commitments and investing in their long-term careers. For example, they suggest that women should be proactive in searching out organisations that have a good reputation for 'women-readiness' and that women put in place a sound infrastructure to manage their work and family commitments. Additionally, Mavin et al. (2015:316) suggest that women need to 'balance exceptional credibility without working too hard to prevent exhaustion'. They highlight that in the context of high-performance work cultures, women need to see 
themselves as 'the project', ensuring that they invest efforts into their own personal development as well as their organisation's development.

Career shocks initiate a period of reflection and decision making about one's future career. Beatty and McGonagle (2016) suggest that proactive career coaching may be of benefit in such circumstances as coaching may facilitate the sensemaking process. Additionally, having access to internal and external female role models in senior positions may provide an effective support network for women struggling to come to terms with the challenges they are encountering within the workplace or their dilemmas regarding their next career steps ( CMI 2013a; CMI 2013b; CMI, 2014; Mavin et al, 2015).

\section{$<\mathrm{b}>$ Conclusion}

Despite growing numbers of women participating in the workplace the number of women in senior management positions is still surprising low. Applying the lens of conservation of resources theory, this chapter presents the experiences of eight women who lost valued resources as a result of career shocks. Their experiences resulted in the women opting to 'step off' their career ladders rather than continuing in their management positions. This chapter puts forward three recommendations to support women incorporating career shocks into their personal career development planning and also to support organisations to incorporate career shocks into their talent retention planning. 


\section{$<\mathrm{b}>$ References}

Akkermans, J. and Kubasch, S. (2017), '\#Trending topics in careers: A review and future research agenda', Career Development international, 22 (6), 586-627.

Akkermans, J., Seibert, S. E. and Moi, S. T. (2018), 'Tales of the unexpected: Integrating career shocks in the contemporary careers literature, $S A$ Journal of Industrial Psychology, 44 (0), 1-10.

Astin, H. S. (1984), 'The meaning of work in women's lives: A sociopsychological model of career choice and work behavior', The Counselling Psychologist, 12 (4), 117-126.

Bagnoli, A. (2009), 'Beyond the standard interview: The use of graphic elicitation and arts-based methods', Qualitative Research, 9 (5), 547-570.

Bardoel, E. A., Pettit, T., M., De Cieri, H. and McMillan, L. (2014), 'Employee Resilience: An Emerging Challenge for HRM', Asia Pacific Journal of Human Resources, 52 (3), 1-19.

Barner, R. (2008), 'The dark tower: Using visual metaphors to facilitate emotional expression during organizational change', Journal of Organizational Change Management, 21 (10, 120 - 137.

Beatty, J. E. and McGonagle, A. (2016), 'Coaching employees with chronic illness: Supporting professional identities through biographical work', International Journal of Evidence Based Coaching and Mentoring, 14 (1), 1-15.

Bright, J. E. H., Pryor, R. G. L. and Harpham, L. (2005), 'The role of chance events in career decision making', Journal of Vocational Behavior, 66 (3), 561-576.

Broussine, Mike (ed.) (2008), Creative methods in organizational research, London: Sage.

Carter, D. A., Simkins, B. J.and Simpson, W. A. (2003), 'Corporate Governance, Board Diversity and Firm Value', The Financial Review, 38 (1), 33-53.

Chartered Institute of Personnel and Development (2018), Diversity and Inclusion at Work: Facing up business case, accessed 04 October 2019 at https://www.cipd.co.uk/Images/diversity-and-inclusion-at-work 2018-facing-up-tothe-business-case-1 tcm18-44146.pdf.

Chartered Management Institute (2013a), Women in management: tackling the talent pipeline, accessed 04 October 2019 at https://www.managers.org.uk/insights/research/currentresearch/2013/november/women-in-management-tackling-the-talent-pipeline

Chartered Management Institute (2013b), Women in Leadership, accessed 04 October 2019 at https://www.managers.org.uk/insights/research/currentresearch/2013/march/women-in-leadership-whitepaper?sc trk=follow\%20hit,\{86CB756B-AB02-44E6-995A305C69252B29\},women+in+leadership 
Chartered Management Institute (2014), Women in Management: The Power of Role Models, accessed 04 October 2019 at

https://www.managers.org.uk/insights/research/current-research/2014/may/thepower-of-role-models?sc trk=follow\%20hit,\{86CB756B-AB02-44E6-995A305C69252B29\},role+models

Chell, Elizabeth. (2004), 'Critical incident technique',in Catherine Cassell and Gillian Symon (eds), Essential guide to qualitative methods in organizational research, London: Sage, pp.45-60.

Cohen, L. and Mallon, M. (2001), 'My Brilliant Career? Using Stories as a Methodological Tool in Careers Research', International Studies of Management and Organisations, 31 (3), 48-68.

Davies, M. (2015), 'Improving the gender balance of British boards', accessed 04 October 2019 at https://www.gov.uk/government/publications/women-on-boards-5year-summary-davies-review

Elraz, H. (2018), 'Identity, mental health and work: How employees with mental health conditions recount stigma and the pejorative discourse of mental illness', Human Relations, 71 (5), $722-741$.

Follmer, K. A. and Jones, K. S. (2018), 'Mental Illness in the Workplace: An Interdisciplinary Review and Organizational Research Agenda', Journal of Management, 44 (1), 325 -351.

Foster, D. (2017), 'The Health and Well-Being at Work Agenda: Good News for (Disabled) Workers or Just a Capital Idea?', Work Employment \& Society, 32 (1), 186-197.

Gorgievski, M. J., Halbesleben, J. R. B. and Bakker, A. B. (2011), 'Expanding the boundaries of psychological resource theories', Journal of Occupational and Organizational Psychology, 84 (1), 1-7.

Halbesleben, J. R. B. (2006), 'Sources of Social Support and Burnout: A MetaAnalytic Test of the Conservation of Resources Model', Journal of Applied Psychology, 91 (5), 1134-1145.

Halbesleben, J. R. B., Neveu, J. P., Paustian-Underdahl, S. C. and Westman, M. (2014), 'Getting to the "COR" understanding the role of resources in conservation of resources theory', Journal of Management, 40 (5), 1334-1364.

Hobfoll, Stevan E. (ed.) (1998), Stress, Culture, and Community: The Psychology and Philosophy of Stress, New York: Plenum Press.

Hobfoll, S. E. (2001), 'The influence of culture, community, and the nested-self in the stress process: Advancing Conservation of Resources theory', Applied Psychology: An International Review, 50 (3), 337-370.

Hobfoll, S. E. (2011), 'Conservation of resource caravans and engaged settings', Journal of Occupational and Organizational Psychology, 84 (1), 116-122. 
Hoffarth, V. B. (1996), 'Perspectives on Career Development of Women in Management', Equal Opportunities International, 15 (3), 21-43.

Holtom, B. C., Lee, T. and Mitchell, T. (2005), 'Shocks as causes of turnover: What they are and how organizations can manage them', Human Resource Management, 44 (3), 337-352.

Ibarra, Herminia (ed.) (2003), Working Identity: Unconventional strategies for reinventing your career, Boston: Harvard Business School Press.

Ibarra, H. and Lineback, K. (2005). 'What's your story?', Harvard Business Review, $83(1), 64-71$.

Johnston, D. W. and Lee, W. (2012), 'Climbing the Job Ladder: New Evidence of Gender Inequality', Industrial Relations, 51 (1), 129-149.

Lazarus, Richard(ed.) (1999), Stress and Emotion, New York: Springer Publishing Company.

Lee, T. W. and Mitchell, T. R. (1994), 'An alternative approach: The unfolding model voluntary employee turnover', Academy of Management Review, 19 (1), 51-89.

Leufstadiusa, C., Eklunda, M. and Erlandsson, L. (2009), 'Meaningfulness in work Experiences among employed individuals with persistent mental illness', Work, 34 (1), 21-32.

Mazzetti, A. (2014), 'Using a visual timeline method in stress research' accessed 04 October 2019 at https://methods.sagepub.com/case/using-a-visual-timeline-methodin-stress-research

Mazzetti, A. and Blenkinsopp, J. (2012), 'Evaluating a visual timeline methodology for appraisal and coping research', Journal of Occupational and Organizational Psychology, 85 (4), 649-665.

Mavin, Sharon, Williams, Jannine, Bryans, Patricia and Patterson, Nicola (2015), 'Woman as Project: Key Issues for Women Who Want to Get On', in Adelina Broadbridgeand Sandra Fielden (eds), Handbook of Gendered Careers in Management: Getting in, Getting on and Getting out, Cheltenham: Edward Elgar Publishing, pp. 305-321.

Meyer, A. D. (1991), 'Visual data in organizational research', Organization Science, 2 (2), 218-36.

O'Neill, D. A. and Bilimoria, D. (2005), 'Women's career development phases: idealism, endurance, and reinvention', Career Development International, 10 (3), 168-189. 
Scott, J. and Hatalla, J. (1990), 'The influence of change and contingency factors on career patterns of college-educated women', The Career Development Quarterly, 39 (1), 18-30.

Seibert, S.E. Kraimer, M.L. Holtom, B.C. and Pierotti, A. J. (2013), 'Even the best laid plans sometimes go askew: Career self-management processes, career shocks, and the decision to pursue graduate education'. Journal of Applied Psychology, 98 (1), 169-182.

Stiles, David (2004), 'Pictorial representation', in Catherine Cassell, and Gillian Symon (eds), Essential Guide to Qualitative Methods in Organizational Research, London: Sage Publications Ltd, pp 127-139.

Sullivan, S., Martin, D., F., Carden, W., A. and Mainiero, L., A. (2003), 'The Road Less Travelled: How to Manage the Recycling Career Stage', Journal of Leadership and Organizational Studies, 10 (2), 34-42.

Sveningsson, S. and Alvesson, M. (2003). 'Managing Managerial Identities: Organizational Fragmentation, Discourse and Identity Struggle', Human Relations, 56 (10), 1163-1193.

Warren, Samantha (2009), 'Visual methods in organizational research', David Buchanan and Alan Bryman (eds), The SAGE handbook of organizational research methods, London: Sage, pp566-582. 